\title{
Control of visual processing by color cueing*
}

\author{
DAVID LaBERGE and LEE S. BROWNSTON \\ University of Minnesota, Minneapolis, Minnesota 55455
}

\begin{abstract}
Eight adult Ss tachistoscopically viewed letter arrays containing 5, 10, 15, 20, or 25 letters inserted into a 5 by 5 matrix. Each array contained one target letter, either an $\mathrm{F}$ or an $\mathrm{H}$. The S's task was to identify which target letter was present in each display. Within an array, a subset of the letters was typed in red ink, and the remaining subset in black ink. In the cued condition, $S$ was told the color of the target letter; in the uncued condition this information was withheld. The results indicated that color cueing significantly increased the accuracy of letter detection. Also significant were total display size, color of cue, and, within the cued condition, size of the target-color subset.
\end{abstract}

Using a Sperling partial report design, Von Wright (1968) studied the selective effect of color cueing in tachistoscopically presented letter arrays. He found that color could be used as a basis for selection of a subset of letters from the total array, although it was not as effective as location, the criterion originally used by Sperling (1960).

Another method commonly used for measuring pattern detection is the forced-choice technique (e.g., Estes, 1972), in which the $S$ is required only to report which of the target letters is present. The purpose of the present study is to determine if color cueing would improve performance in this task as well.

\section{METHOD}

The set of stimuli consisted of 288 displays, each containing 5 to 25 uppercase letters inserted into a 5 by 5 matrix. Each row and each column of the matrix always contained the same number of letters. The letters were typed in elite type in either red or black ink. For each display in the set, there was another display identical to it in every respect except that the colors were reversed. Both the columns and the rows of the matrix were single spaced. Each display contained either one $\mathrm{H}$ or one $\mathrm{F}$, but never both. For each display in the set, there was another display identical to it in every respect except that one contained an $\mathrm{H}$ and the other contained an $\mathrm{F}$. There were two cueing conditions: (1) 5 cued letters (including the $\mathrm{F}$ or $\mathrm{H}$ ) of one color, with $0,5,10,15$, or 20 distractor letters of the other color; and (2) 10 cued letters (including the F or $\mathrm{H}$ ) of one color, with $0,5,10$, or 15 distractor letters of the other color. The 5 or 10 cued letters were distributed such that a color-cued letter appeared once in each row and column for the 5-cued set and twice in each row and column for the 10-cued set. Target positions were balanced across all cued positions. No vowels ever appeared in the displays.

The letter matrix cards were presented in the "stimulus" channel of a Scientific Prototype two-channel tachistoscope, and were uniformly illuminated at a luminance of $1.5 \log \mathrm{fL}$. The background field was provided by a similar white card, containing a small black fixation point at the position corresponding to the center of the letter matrix. This card was presented in the "blank" channel and was uniformly illuminated at a luminance of $0.5 \log \mathrm{fL}$.

*This research was supported by United States Public Health Service Grant MH-16270-05 and by the Center for Research in Human Learning through National Science Foundation Grant GB-17590.
The $S$ sat in front of the tacinistoscope and observed the displays through a viewing hood. For each trial, a buttonpush by the $S$ initiated the presentation of the letter matrix at the moment he wished following E's vocal ready signal. The S's task was to identify and name the letter, $\mathrm{F}$ or $\mathrm{H}$, which appeared in each display. Following S's response, E read aloud the correct answer.

The first day of the experiment was a practice session, given to all Ss in order to stabilize performance before the data for analysis were taken. This session consisted of the repeated presentation of a subset of the letter matrices, with compensatory adjustments of the exposure time, until performance stabilized at a hit rate of $68-82 \%(3,4$, or 5 errors out of 16 trials) for a single exposure time. The exposure times ranged from $20 \mathrm{msec}$ to $110 \mathrm{msec}$, with a median of $50 \mathrm{msec}$. The $\mathrm{S}$ was then assigned this same exposure time on all subsequent sessions. The practice set was composed of the 16 matrices containing 5 black letters with 20 red distractor letters. This same set was used for the warm-up trials which preceded each daily session.

The Ss completed four test sessions, one session per day, and each session consisted of 16-warm-up trials from the practice set and 288 test trials. The Ss ran on the cued and uncued conditions on alternate days. In an uncued session, all 288 letter matrices were presented in random order. In a cued session, all 144 letter matrices of one color, in random order, preceded the 144 letter matrices of the other color. The S was always told whether he was in the cued or uncued condition, and, if he was in the cued condition, which cueing color was being presented. The $\mathrm{S}$ was allowed to pace the rate of presentation and to pause at any time. The $E$ indicated when the session was $1 / 4,1 / 2$, and $3 / 4$ completed.

\section{RESULTS AND DISCUSSION}

Data from the last 4 days' sessions were used in the analysis. Figure 1 shows the proportion of correct detection responses for the eight Ss as a function of display size under the two cueing conditions. Each point is based on 64 observations per $S$ or a total of 512 observations. A 6-way analysis of variance of the error data from display sizes of $10,15,20$, and 25 indicated significant effects of (a) total display size $[F(3,411)=39.13, \quad p<.001], \quad$ (b) cueing condition $[F(1,411)=23.15, \quad p<.001], \quad(c)$ replications $[F(1,411)=31.69, p<.001]$, (d) Ss $[F(7,411)=18.12$, $\mathrm{p}<.001]$, and $(\mathrm{e})$ color of cue $[\mathrm{F}(1,411)=16.46$, 


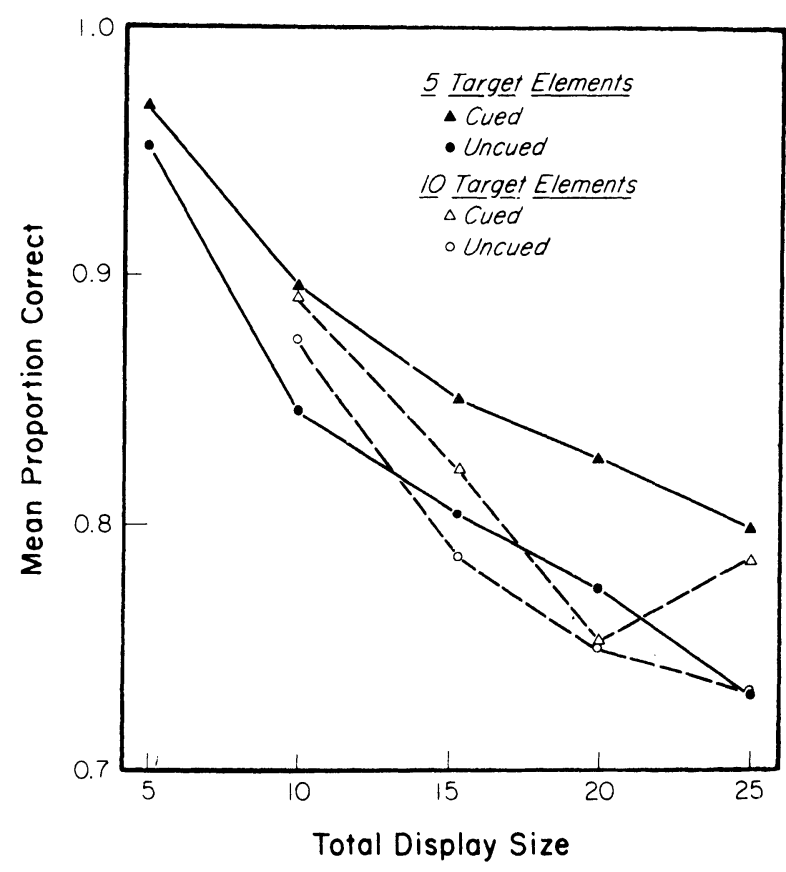

Fig. 1. Accuracy of letter detection as a function of the size of the displav, in which a set of 5 or 10 letters was colored. The term "target" denotes the set of colored items which contained the $\mathrm{H}$ or $\mathrm{F}$.

$\mathrm{p}<.001]$. An orthogonal contrast revealed that, within the color-cued condition, number of cued letters was significant $[F(1,411)=6.44, p<.05]$. None of the interactions was significant. An independent analysis of variance compared means at the display size of 5 , yielding an $\mathrm{F}(1,7)=2.333(\mathrm{p}>.05)$.

The main findings of interest are that detection accuracy was greater under color-cueing conditions, and, within a display of a constant size, accuracy was greater for 5 cued elements than for 10 . These data support the hypothesis that Ss can employ color information to assist the detection of a target letter.

The detection of letters under the cued-color conditions apparently is strongly influenced by the number of noncued (noise) letters present in the display, in view of the substantial slope of the cued curves in Fig. 1. This would imply that selection by color is not complete. Conceivably the presence of noise letters would interfere with initial separation of letters of the cued color prior to letter processing, or it could interfere with letter processing itself or both. Unfortunately, the present data do not clearly distinguish among these alternatives.

When the slopes of the cued and uncued curves are compared, it appears that they are almost parallel over the range of display sizes of 10 to 25 items. This is the range in which noise items occur in the displays. However, the interaction of Cueing Condition by Display Size was close to significance, suggesting that there may be a small difference in slope. Nevertheless it seems somewhat surprising that a more substantial slope difference was not found, because the advantage of reducing the processing of a set of items to a constant subset should increase as display size increases.

\section{REFERENCES}

Estes, W. K. Interactions of signal and background variables in visual processing. Perception \& Psychophysics, 1972, 12, 278-286

Sperling, G. The information available in brief visual presentations. Psychological Monographs, 1960, 74, No 11. Von Wright, J. M. Selection in visual immediate memory. Quarterly Journal of Experimental Psychology, 1968, 20, 62-68.

(R eceived for publication July 29, 1974.) 